\title{
Q uantitative studies of the vasculature of the carotid body in the chronically hypoxic rat
}

J.A. Clarke ${ }^{1}$ M. de B. Daly ${ }^{1}$, J.M. Marshall2, H.W. Ead ${ }^{\dagger}$ and E.M. Hennessy ${ }^{3}$

\author{
${ }^{1}$ Department of Physiology, The Royal Free and University College Medical School, \\ London, UK \\ 2Department of Physiology, the Medical School, University of Birmingham, \\ Birmingham, UK \\ ${ }^{3}$ Department of Environmental and Preventive Medicine, Wolfson \\ Institute of Preventive Medicine, Q ueen Mary and Westfield College, London, UK
}

\section{Correspondence \\ M. de B. Daly \\ Royal Free and University \\ College Medical School \\ Royal Free Campus \\ Rowland Hill Street \\ London NW 3 2PF \\ UK \\ Fax: +44-171-433-1921}

Research supported by grants from British Telecommunications plc to

J.A. Clarke and from the British

Heart Foundation to $M$. de B. Daly and to J.M. Marshall. tDeceased.

Some of these data were previously reported in abstract form in Ref. 10 (Journal of Physiology (1996) 495: 29P).

Received January 29, 1999 Accepted January 3, 2000

\section{Abstract}

The carotid bodies of rats made chronically hypoxic by breathing $12 \%$ $\mathrm{O}_{2}$ in a normobaric chamber (inspired $\mathrm{PO}_{2} 91 \mathrm{mmHg}$ ) were compared with those of controls. Serial $5-\mu \mathrm{m}$ sections of the organs were examined using an interactive image analysis system. The total volume of the carotid bodies was increased by $64 \%$. The total vascular volume rose by $103 \%$ and was likely due to an increase in size of the large vessels ( $>12 \mu \mathrm{m}$ lumen diameter) because the small vessel (5-12 $\mu \mathrm{m}$ lumen diameter) volume did not increase significantly while the small vessel density tended to decrease. The extravascular volume was increased by $57 \%$. Expressed as a percentage of the total volume of the organ, the total vascular volume did not change, but the small vessel volume was significantly decreased from 7.83 to $6.06 \%$. The large vessel volume must therefore have been increased. The proportion occupied by the extravascular volume was virtually unchanged (84 vs $82 \%$ ). In accordance with these findings, the small vessel endothelial surface area per unit carotid body volume was diminished from 95.2 to $76.5 \mathrm{~mm}^{-1}$, while the extravascular area per small vessel was increased from 493 to $641 \mu \mathrm{m}^{2}$ or by $30 \%$. In conclusion, the enlargement of the carotid body in chronic hypoxia is most likely due to an increase in total vascular volume, mainly involving the "large" vessels, and to an increase in extravascular volume. This is in contrast to our previously published findings indicating that in the spontaneous insulin-dependent diabetic rat the enlargement of the carotid body is due solely to an increase in extravascular volume.

\section{Introduction}

Chronic hypoxia causes enlargement of the carotid bodies as first shown by AriasStella (1) and confirmed since in several studies in humans (2) and cattle living at high altitude (3). It also occurs in animals exposed to an environment of lowered $\mathrm{PO}_{2}$ at sea level and this enlargement is reversed by
Key words

- Rat carotid body

- Morphology

- Chronic hypoxia 
organ or to the appearance of the systemic arteries, arterioles and the microvasculature in the organ under these conditions.

In this paper we report the results of an investigation to establish the role that vascular structures might play in the enlargement of the carotid body in the chronically hypoxic rat. The various compartments of the carotid body were analysed quantitatively and particular attention was paid to the volume and proportion of the small vessels (5$12 \mu \mathrm{m}$ in diameter) in the vascular compartment together with the density of small vessels. The term "small vessels" has been defined and used previously $(8,9)$.

This study also constitutes a further investigation by us of the pathophysiological conditions affecting the microvasculature of the carotid body, thereby permitting a comparison of the effects of chronic hypoxia in the organ with those occurring in the spontaneous insulin-dependent diabetic rat $(9,10)$.

\section{Material and Methods}

Carotid bifurcation regions were examined bilaterally in 5 control adult male rats (Wistar strain), age 77 days, 3 of which had been prepared at an earlier date as part of another study, and in 3 male rats age 80 days and of similar weight (Table 1), made chronically hypoxic by breathing a mixture of $12 \%$ $\mathrm{O}_{2}$ in $88 \% \mathrm{~N}_{2}$ in a normobaric chamber for 31 days (inspired $\mathrm{PO}_{2}$ approximately 91 mmHg) (Supplier: Biomedical Services Unit, University of Birmingham, Birmingham, UK). The carotid bodies were analysed quantitatively, particular attention being paid to the volume and proportion of the "small" vessels (5-12 $\mu \mathrm{m}$ lumen diameter) and "larger" vessels ( $>12 \mu \mathrm{m}$ lumen diameter) in the vascular compartment, as defined by us previously $(8,9)$. A complete description of the perfusion-fixation technique used to examine the carotid bifurcation regions in rats has been given previously $(9,11,12)$. Briefly, the animals were anaesthetized with pento- barbitone sodium (Sagatal, Rhöne Mérieux; $40 \mathrm{mg} / \mathrm{kg}$, intraperitoneally), heparinized, submitted to median sternotomy, and quickly bled to death via a large incision in the right atrium. Immediately, perfusion of the carotid bifurcations was begun via the ascending aorta with sodium chloride solution (154 $\mathrm{mmol} / \mathrm{l}$ ) at a pressure of $100 \mathrm{mmHg}$ and temperature of $37^{\circ} \mathrm{C}$, the arterial pressure in the chronically hypoxic group being the same as in the control group breathing room air (13). Perfusion was followed by $3 \%$ glutaraldehyde in isotonic phosphate buffer, $\mathrm{pH}$ 7.3 , at the same pressure and temperature for 5 min. Each animal was stored overnight with the level of the carotid bifurcation regions 1-2 $\mathrm{cm}$ above that of the heart to maintain a normal venous pressure in these regions and to prevent retrograde movement of blood-stained fluid and occasional red cells from the trunk of the animal into the carotid body vasculature. Each carotid bifurcation region was prepared routinely for light microscopy and ribbons of transverse serial 5 - $\mu \mathrm{m}$ sections from paraffin wax blocks were cut and stained using a modification of the Martius Scarlet Blue method for fibrin $(9,12)$.

The various compartments of the carotid body were determined quantitatively using an interactive image analysis system. From an analysis of the histological sections taken at sample intervals of $25 \mu \mathrm{m}$, the following information was obtained by using Simpson's rule (5): 1) carotid body area and volume; 2) total vascular area and volume; 3 ) extravascular area and volume by subtraction (7); 4) small vessel endothelial surface area, i.e., a measurement of the surface area actually based on the external surface of the endothelial cells; 5) large vessel endothelial surface area, and 6) ratio of small vessel endothelial surface area to the carotid body volume. Values for extravascular area of the carotid body and small vessel area were obtained by summing the respective areas of individual sections of the total organ (9).

Group results are expressed as mean val- 
ues \pm SD. For each measure the outcome variable was the mean for the left and right carotid body. Student's unpaired $t$-test was used to compare the means for hypoxic and control rats. We do not know whether assumptions regarding normality are appropriate and therefore the statistical significance of the results should be interpreted with caution, but nonparametric tests with such small numbers would not have had the power to detect statistical significance. An assumption of similar variances gives more conservative results than the method for different variances and was therefore used. Stata (14) was used for the statistical analysis. Values were taken as significant if $\mathrm{P}<0.05$.

\section{Results}

\section{Microvasculature of the carotid body}

We have described this previously in detail (9), but we shall briefly review the relevant points which are applicable to this paper. Classically, the carotid body artery, having originated from the external carotid artery, approaches the caudal pole of the organ and branches at its caudal margin into several arterioles. Thereafter, two distinct circulatory routes through the organ are discernible. Firstly, there is the 'straight through' circulation which consists of three or four small arterioles confined to the central connective tissue framework of the carotid body. Secondly, there is the 'parenchymal circulation' which consists of a dense capillary network which fans out from the caudal pole of the carotid body and travels rostrally to supply the type 1 and type 2 cells. This arrangement was clearly observed by us in a computer reconstruction of the vasculature of the rat carotid body (15; Clarke JA, Duff MJB and Ip HH-S, unpublished observations).

The general topographical description of the carotid bodies agreed well with that given previously (6) and is shown in Figure 1 taken from a normal animal (A) and a hypoxic animal (B). The type 1 cells of the carotid bodies of the chronically hypoxic rats showed no evidence of recent hyperplasia. The nuclei of the type 1 cells and type 2 cells, which could be unequivocally identified, were uniformly devoid of metaphase spindles or other features of chromosome aggregation. Measurements of type 1 cells in randomly selected sections indicated that the size of the cells fell within the accepted normal range of $15-30 \mu \mathrm{m}(16)$, but this variable has not been made the subject of a special study. The endothelial cells of the small vessels were prominent in contrast to those of the control organs, being more intensely stained. This resulted in many of the vessels appearing to have distinct cellular crescents adjacent to the lumen. These features were absent in the controls (Figure 1A,B). The nuclei of the endothelial cells showed no evidence of recent mitosis, as metaphase chromosome configuration was absent. No evidence of systemic arterial disease was noted in the ca-
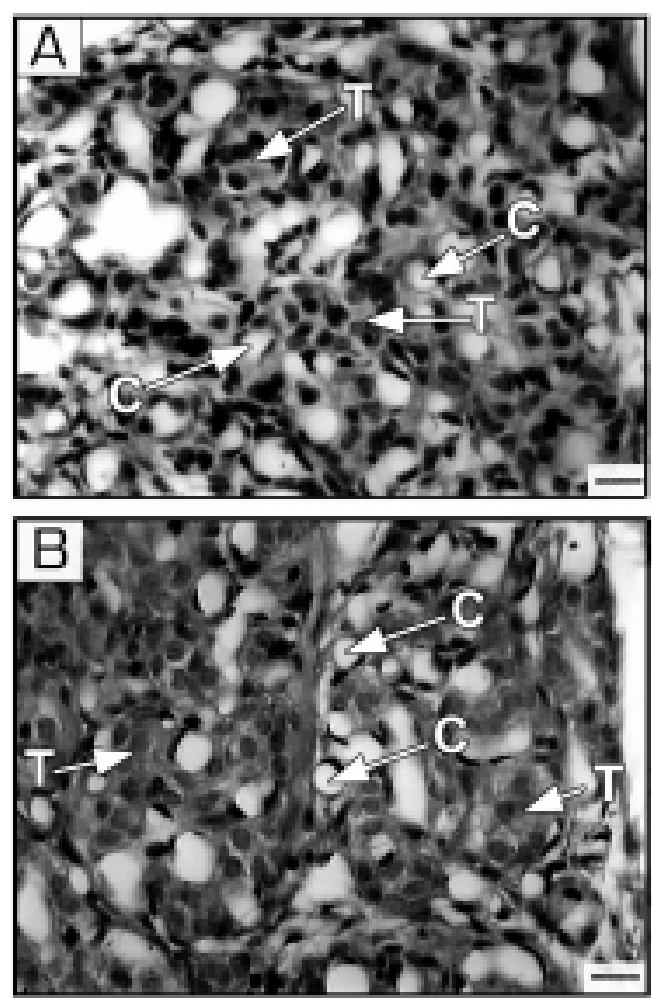

Figure 1 - Photomicrographs of the carotid body from a control rat (A) and chronically hypoxic animal (B). Section thickness, 5 $\mu \mathrm{m}$. Martius Scarlet Blue method of staining. Bar, $10 \mu \mathrm{m}$. T, Type 1 cells; C, capillary. Note that the endothelial nuclei are not particularly conspicuous in $A$, but are prominently stained in B. Also in B, there is no evidence of hyperplasia or mitotic figures. 
rotid stem arteries or in their major branches in either the control or hypoxic group of animals. The capillary bed was patent in all parts of the carotid bodies, although in occasional sections, small areas of closely arranged type 1 and 2 cells, constituting less than $5 \%$ of the field, were seen which had no apparent accompanying capillaries.

The computerized analysis of some hundreds of sections of the carotid bodies revealed the following findings, although they are not all apparent in a comparison of just two selected sections shown in Figure 1A,B. Although the rostral-caudal length of the carotid bodies was unchanged in the hypoxic group, the total volume was increased by $64 \%$ (Table 1). There was a significant increase in total vascular volume of $103 \%$ which must have been due to an increase in size of the large vessels $>12 \mu \mathrm{m}$ in diameter because the small vessel volume $(5-12 \mu \mathrm{m}$ in diameter) did not change (Table 1). In the chronically hypoxic animals, the venules situated at the periphery of the organ, but within

Table 1 - Dimensions of control and hypoxic rat carotid bodies (CB).

Total vascular, small vessel (SV) and extravascular volumes are also expressed as a percentage of the total volume of the organ. Values are reported as means \pm SD for carotid bodies of 5 control and 3 hypoxic rats. $P$ values were determined by Student's unpaired t-test.

\begin{tabular}{|c|c|c|c|}
\hline & Control & Hypoxic & $P$ value \\
\hline Body weight (g) & $258.4 \pm 18.5$ & $275 \pm 15$ & 0.246 \\
\hline $\begin{array}{l}\text { Rostral-caudal } \\
\text { length CB }(\mu \mathrm{m})\end{array}$ & $423.4 \pm 70.1$ & $371 \pm 66.7$ & 0.34 \\
\hline $\begin{array}{l}\text { Carotid body volume } \\
\qquad\left(\mathrm{mm}^{3} \times 10^{-3}\right)\end{array}$ & $12.7 \pm 4.95$ & $20.8 \pm 2.6$ & 0.04 \\
\hline $\begin{array}{l}\text { Total vascular volume } \\
\left(\mathrm{mm}^{3} \times 10^{-3}\right)\end{array}$ & $1.87 \pm 0.94$ & $3.8 \pm 1.2$ & 0.043 \\
\hline $\begin{array}{l}\text { Total vascular } \\
\text { volume }(\%)\end{array}$ & $15.3 \pm 5.7$ & $18.0 \pm 3.87$ & 0.50 \\
\hline $\begin{array}{l}\text { SV volume } \\
\qquad\left(\mathrm{mm}^{3} \times 10^{-3}\right)\end{array}$ & $1.01 \pm 0.39$ & $1.27 \pm 0.22$ & 0.27 \\
\hline SV volume (\%) & $7.83 \pm 0.63$ & $6.06 \pm 0.46$ & 0.0058 \\
\hline $\begin{array}{l}\text { Extravascular volume } \\
\qquad\left(\mathrm{mm}^{3} \times 10^{-3}\right)\end{array}$ & $10.8 \pm 4.5$ & $17.0 \pm 1.43$ & 0.033 \\
\hline $\begin{array}{l}\text { Extravascular } \\
\text { volume (\%) }\end{array}$ & $84.3 \pm 6.53$ & $82.0 \pm 3.86$ & 0.61 \\
\hline
\end{tabular}

the definable irregular border of the carotid body, were more conspicuous than in the controls and presumably contributed to the increase in total vascular volume. By subtraction, extravascular volume was found to be increased significantly by $57 \%$ (Table 1 ). The sizes of the total vascular, small vessel and extravascular volumes expressed in proportion to the total volume of the carotid body are also shown in Table 1 . The value for total vascular volume, expressed as a percentage of the total volume of the organ, tended to increase from $15.3 \%$ in the controls to $18.0 \%$ in the hypoxic group, that is, by $17.6 \%$, but this was not statistically significant. However, the percent small vessel volume was significantly reduced, whereas the proportion of the carotid body occupied by the extravascular cells and tissues was unaffected (Table 1).

The values for the endothelial surface areas are shown in Table 2. In keeping with the reduced proportion of the small vessel compartment in the carotid bodies of the hypoxic animals, small vessel endothelial surface area per unit carotid volume was significantly diminished. On the other hand, the increased volume of the large vessels in the hypoxic carotid bodies tended to be associated with an augmented large vessel endothelial surface area both in absolute units and when expressed per unit carotid body volume, but the differences were not significant (Table 2). Table 2 also provides mean data for variables based on a sampling interval of $25 \mu \mathrm{m}$. In the hypoxic animals there was a significant increase of $73 \%$ in extravascular area and of $30 \%$ in extravascular area per small vessel. Correspondingly, the density of the small vessels was significantly reduced by about the same proportion.

\section{Discussion}

We have confirmed that in the chronically hypoxic rat there is an increase in total volume of the carotid body (for references, 
see Introduction). The new information is that, by using image analysis techniques, this increase is found to be due to changes in the morphology of two compartments in the organ: a) an augmented total vascular volume, and b) an increase in extravascular volume.

Other investigators (17) observed a generalised increase in vascularity of the hypoxic carotid body, but gave no indication of the luminal diameter of the affected vessels. In particular, they drew attention to dilated vessels and blood 'sinuses', a category of blood vessel which does not occur in the organ. A critical analysis of their technique indicates that their observations may be due in part to the method of preparation of the carotid bodies, which were fixed in situ in the anaesthetised animal by dripping $8 \%$ glutaraldehyde on to the carotid bifurcation regions until the animals died or were killed by thoracotomy. As a consequence of this fixation method, venous congestion of cardiac origin must have occurred due to toxicity and/or asphyxia, so that a rise in venous pressure would have affected the carotid body vasculature passively. In another investigation (18) concerning the effect of sympathectomy on long-term hypoxic rats, the authors gave insufficient information on their methods to allow us to comment on their findings of different sizes of blood vessels within the organ. We emphasise that the changes observed in the two compartments of the carotid body in our experiments occurred in the absence of an increase in venous pressure in vivo (19) and that during the perfusion-fixation procedure we used, retrograde filling and artificial distension of the organ's venous microvasculature after death were prevented by raising the animal's head just above the level of the thorax.

Our results showed that the total vascular volume and extravascular volume increased pari passu with the total volume of the organ, so that when these variables are expressed as a percentage of the total volume of the organ there is no significant difference between the values for the normal and hypoxic animals. Analysis of the large vessel compartment (vessels of $>12 \mu \mathrm{m}$ in diameter) was difficult because of the variable topography of the venous plexus, particularly at the periphery of the carotid body. Nevertheless, the observation that the total vascular volume of the carotid body increased by $103 \%$ in hypoxic animals, even though the 'small vessel' volume showed no significant increase, implies that there must have been an increase in the 'large vessel' compartment. Indeed, a more detailed analysis of the results showed that the mean percentage of total vascular volume did increase appreciably in the carotid bodies of the hypoxic group of animals, although this increase did not reach statistical significance. This was due to the variability of the relative increases in total vascular volume and in the total volume of each organ. By contrast, in the case of 'small vessels', the absolute small vessel volume did not change in the hypoxic

Table 2 - Vascular endothelial surface areas of control and hypoxic rat carotid bodies (CB), mean extravascular area (EVA), number of small vessels, extravascular area per small vessel, small vessel density, and total number of small vessels, all based on a sampling interval of $25 \mu \mathrm{m}$.

Values are reported as means \pm SD for carotid bodies of 5 control and 3 hypoxic rats. P values were determined by Student's unpaired t-test. EV , Extravascular volume; LV, large vessel; SV, small vessel.

\begin{tabular}{|c|c|c|c|}
\hline & Control & Hypoxic & $P$ value \\
\hline Mean EVA $\left(\mu m^{2}\right)$ & $26599 \pm 8161$ & $46122 \pm 4196$ & 0.0093 \\
\hline Mean No. of SV & $54.7 \pm 15.4$ & $72.3 \pm 5.2$ & 0.11 \\
\hline EVA per SV $\left(\mu \mathrm{m}^{2}\right)$ & $493 \pm 50.4$ & $641 \pm 49.1$ & 0.0066 \\
\hline SV density $\left(\mathrm{mm}^{2}\right)$ & $2067 \pm 220$ & $1581 \pm 119$ & 0.014 \\
\hline Total No. of SV & $936 \pm 353$ & $1129 \pm 163$ & 0.42 \\
\hline $\begin{array}{l}\text { SV endothelial surface } \\
\text { area }\left(\mathrm{mm}^{2}\right)\end{array}$ & $1.22 \pm 0.47$ & $1.6 \pm 0.33$ & 0.265 \\
\hline $\begin{array}{l}\text { SV endothelial surface } \\
\text { area per unit CB } \\
\text { volume }\left(\mathrm{mm}^{-1}\right)\end{array}$ & $95.2 \pm 10.4$ & $76.5 \pm 7.0$ & 0.032 \\
\hline $\begin{array}{l}\text { SV endothelial surface } \\
\text { area per unit EW } \\
\left(\mathrm{mm}^{-1}\right)\end{array}$ & $112.5 \pm 20.9$ & $94.4 \pm 12.0$ & 0.18 \\
\hline $\begin{array}{l}\text { LV endothelial surface } \\
\text { area }\left(\mathrm{mm}^{2}\right)\end{array}$ & $0.98 \pm 1.17$ & $1.91 \pm 0.80$ & 0.28 \\
\hline $\begin{array}{l}\text { LV endothelial surface } \\
\text { area per unit CB } \\
\text { volume }\left(\mathrm{mm}^{-1}\right)\end{array}$ & $77.4 \pm 84.7$ & $89.3 \pm 29.4$ & 0.81 \\
\hline
\end{tabular}


group of animals, so that when expressed as a percentage of the total volume of the organ, the percentage value actually decreased significantly. In accordance with this, the small vessel endothelial surface area expressed per unit carotid body volume, and the density of the small vessels in the organ were both diminished.

A question arises as to the possible mechanisms underlying these observations. The finding that the size of the 'small vessel' volume did not change in the hypoxic carotid body and that there was a reduction in the volume of this compartment when expressed as a percentage of the total volume of the organ can be explained solely in terms of the absolute increase in total volume. We have therefore concentrated below on the explanation for the changes in the large vessels $(>12 \mu \mathrm{m}$ in diameter) and in the extravascular extracellular compartments.

Firstly, we considered whether the observed changes in the carotid bodies of chronically hypoxic rats might reflect angiogenesis. Tissue hypoxia is known to stimulate capillary angiogenesis in tissues other than the carotid body (20) and in the carotid body itself mitotic figures have been reported in endothelial cells of the hypoxic organ (21). Particular attention was, therefore, paid to this issue in the present study. No evidence of mitoses was seen in any part of the extensive capillary network within the organ although endothelial cell nuclei were prominent and their deeply stained crescentic appearances were striking. However, we have to acknowledge that the absence of observable mitotic spindle does not exclude the possibility that mitosis had occurred prior to 31 days when the hypoxic animals were examined. As noted above, however, the size of the small vessel compartment was actually decreased in the hypoxic carotid bodies. Therefore it is very unlikely that angiogenesis occurred at the level of capillaries.

Secondly, changes in the vascular com- partment of the hypoxic carotid body might be due to remodelling of the vasculature. Arteriolar remodelling has been shown to occur in the skeletal muscles of rats exposed to chronic hypoxia such that capillaries gain smooth muscle and become arterioles (22). The arrangement of the arteriolar vessels in the carotid body is unusual in that those supplying capillaries to groups of type 1 and type 2 cells are largely confined to the caudal pole of the organ. Furthermore, the distribution of blood flow within the organ is uneven and only a small proportion, up to $8 \%$, of the total blood flow through the carotid body supplies type 1 and type 2 cells $(9,23)$. The remainder bypasses the parenchymal tissue via 'straight through' channels which are largely arteriolar and are confined to the more central parts of the connective tissue framework of the carotid body. Changes in arteriolar arrangements in the central part of the organ would therefore be apparent immediately in serial sections, but this was not observed. Furthermore, careful examination of all the serial sections from the peripheral parts of the carotid bodies from hypoxic animals did not reveal smooth muscle cells surrounding the endothelial cells of capillaries adjacent to type 1 and type 2 cells which would have been indicative of the formation of new arterioles. Such an arrangement would have resulted in a striking alteration in the appearance of the carotid body microvasculature, and again this was not observed.

Thirdly, the question arises as to whether remodelling of the larger peripheral veins could account for the increase in the large vessel volume such that post capillary venules and small venous vessels gained smooth muscle and became vessels $>12 \mu \mathrm{m}$ in diameter. The results of our analyses do not enable us to state whether the increase in large vessel volume was due to an increase in the number of veins $>12 \mu \mathrm{m}$ in diameter and/or in the diameter of the venous vessels already existing in the organ. It must be admitted that the peripheral venous network of the carotid 
body has such a variable morphology that, if remodelling had occurred prior to 31 days it would have been very difficult to detect in our sections. However, our feeling is that it was the diameter of the venous vessels rather than their number that increased. Certainly, in our histological sections the venous network of the cervical striated muscle and connective tissue surrounding the carotid body was more prominent in the chronically hypoxic animals, and this was apparently due to the fact that the venous vessels were larger than in the control animals. We have already discounted (see above) the possibility that in our preparations a rise in venous pressure could have contributed to enlargement of the large vessel compartment. However, an explanation may be found in the changed morphology of the endothelial cells of the hypoxic carotid bodies, i.e., the prominent nuclei (see above). In keeping with current understanding of the effects of hypoxia on endothelial cells $(24,25)$, we suggest that substances such as nitric oxide, adenosine and prostaglandins are released during chronic hypoxia to cause the smooth muscle of the arterioles and venous vessels to relax. Furthermore, if this is the case, then as a consequence of the vasodilatation, and perhaps as a consequence of the release of substances that increase vascular permeability, we suggest there is a greater filtration of fluid out into the interstitium which would in turn have contributed to the augmented extravascular volume of the organ (see below). These hypotheses are in keeping with the finding that enlargement of the organ is almost completely reversed when the arterial $\mathrm{PO}_{2}$ is restored to normal (26).

An increase in the number of type 1 cells might have contributed to the increase in the extravascular volume of the carotid body. We are aware of studies $(6,21)$ reporting changes in the morphology of type 1 cells. Even so, in random selected sections of the carotid bodies from hypoxic animals, we found that the diameter of type 1 cells fell within the normal range (16) and we did not see any evidence of mitotic spindles in type 1 cells. Various recent studies on the development of neural crest cells $(27,28)$ have shown that cells from 'neural crest-derived ectomesenchyme' have the ability to divide and undergo specialised development. Presumably, type 1 cells of the carotid body originate from neural crest cells which have migrated through the 3rd pharyngeal arch, thus providing an explanation for the innervation of the organ via the carotid sinus branch from the 1X cranial nerve. Whether type 1 cells which have reached their final destination still have the capacity to divide is unknown. We can say only that type 1 cells may have undergone a brief period of mitosis prior to 31 days of chronic hypoxia. However, we suggest that a brief wave of cellular proliferation would have made a minimal contribution to the overall increase in size of the organ reported under conditions of chronic hypoxia.

The reversal of the size of the carotid body when the arterial $\mathrm{PO}_{2}$ is returned to normal (26) also argues against an increasing number of type 1 cells during the period of chronic hypoxia. An increase in the number of cells is irreversible unless the cell numbers are reduced by apoptosis. Such a situation would demand the appearance of macrophages and other components of the system concerned with removal of cell debris. As far as we are aware, no study has ever reported this in the carotid body of individuals that were returned to normoxic air-breathing. Therefore, we think it is reasonable to assume that the recovery of the size of the carotid body is not due to apoptosis, but must be due to a reduction in the size of the vascular and extravascular extracellular compartments. It follows that if the size and number of type 1 cells remain relatively constant, the increase in extravascular volume in the chronically hypoxic carotid body must be due to an increase in size of the extravascular, extracellular space, i.e., inter- 
stitial space. Therefore, in summary, we propose that in the chronically hypoxic carotid body, dilatation of arterioles and particularly of the venous vessels of $>12 \mu \mathrm{m}$ together with increased filtration of fluid into the interstitium are mainly responsible for increasing the size of large vessel and extravascular compartments. Clearly, further investigations will be required to test these hypotheses.

It is of interest to compare our results with previous reports $(10,11)$ on changes observed in the carotid body of the spontaneously insulin-dependent diabetic rat. The cause of the enlargement of the carotid body in this condition differed from that seen in the hypoxic animals. In the diabetic rat, the total vascular volume did not change and was even diminished when expressed as a percentage of the total volume of the organ. Rather, the increased total volume of the diabetic rat carotid body was entirely attributable to an increase in the extravascular volume, in contrast to the hypoxic state where the increased extravascular volume was only a partial contributor.

\section{Possible significance of morphological changes in the carotid body to acclimatiza- tion to chronic hypoxia}

Exposure to a steady-state chronic hypoxic environment in humans and other species leads to an increase in pulmonary ventilation which is characterised by an immediate increase followed by a time-dependent progressive rise in minute volume and a fall in alveolar and arterial $\mathrm{PCO}_{2}$, termed the ventilatory acclimatization to hypoxia (VAH; 29,30). Although the time course of VAH varies between species, the evidence indicates that the carotid body chemoreceptors play an important role in the genesis of $\mathrm{VAH}$ $(29,30)$. The discharge in the chemoreceptor fibres of the carotid sinus nerve increases with a time course similar to that of pulmonary ventilation (30-32), and there is a time- dependent increased sensitivity of the oxygen-responsive mechanism (33). In animals with denervated carotid bodies, VAH is significantly attenuated $(29,34)$. There is still doubt about the mechanism underlying the increased hypoxic sensitivity of the carotid bodies in VAH. Hypoxia augments the activity of the efferent fibres in the carotid sinus nerve (35), but such activity is unlikely to be a cause of the progressive increase in the chemoreceptor discharge in the $\mathrm{VAH}$, since it is predominately inhibitory to the carotid body (36). Other mechanisms have been considered, but the evidence has been somewhat equivocal, e.g., 'down-regulation' of the inhibitory action of dopamine and a noradrenergic mechanism (30). The results of the present study suggest an alternative explanation based on the observed morphological changes in the carotid body. It has been established that under normoxic conditions the mean carotid body $\mathrm{PO}_{2}$ is about 25 $\mathrm{mmHg}$ in the cat (37). It must be assumed that whatever the mechanism of signal transduction, the activity of the organ, as indicated by the discharge of impulses in afferent fibres in the carotid sinus nerve, will be dependent upon the level of tissue $\mathrm{PO}_{2}$. Tissue $\mathrm{PO}_{2}$ depends upon a number of factors: arterial $\mathrm{PO}_{2}$, tissue oxygen consumption, tissue blood flow and the diffusion distance between the capillaries and tissue according to the Krogh-Erlang equation (38). We suggest that VAH of carotid chemoreceptor origin could be accounted for, at least in part, by the gradual morphological changes described here involving an increase in extravascular volume, a reduction in small vessel density and an increase in extravascular volume per small vessel. This would have the effect of increasing the distance between the vessels and the centre of the type 1 and 2 cells, thereby causing a progressive lowering of the tissue $\mathrm{PO}_{2}$ and hence an increase in chemoreceptor activity. If, as we have proposed, the increase in extravascular volume is the result of an increase in the volume of 
the interstitial space, and possibly of the type 1 and 2 cells as well, this would further increase the mean capillary-tissue distance.

It is well recognised that on return to sealevel following a stay at high altitude, some hyperventilation persists temporarily (ventilatory deacclimatization; 39). It appears that this phenomenon is not simply a manifestation of the same mechanism that accounts for $\mathrm{VAH}$, but is in part secondary to respiratory alkalosis that develops during the phase of hyperventilation (40). Nevertheless, the sensitivity of the carotid bodies to acute hypoxia presumably remains increased, at least during the immediate period of deaccli- matization (31) and in time gradually returns to normal. On the basis of the observations reported here, we suggest that this phenomenon could be attributed to initial persistence, followed by reversal, of the morphological changes evoked in the first place by chronic hypoxia.

\section{Acknowledgments}

We wish to acknowledge the technical expertise of Barbara A. Jackson, FIBMS, Department of Histopathology, St. Margaret's Hospital, Epping, Essex, in the preparation of the material.

\section{References}

1. Arias-Stella J (1969). Human carotid body at high altitudes. In: 69th Program and Abstracts of the American Association of Pathologists and Bacteriologists, San Francisco. Item 150.

2. Heath $D \&$ Smith $P$ (1985). The Pathology of the Carotid Body and Sinus. Arnold, London.

3. Edwards $C$, Heath $D$, Harris $P$, Castillo $Y$, Krüger H \& Arias-Stella J (1971). The carotid body in animals at high altitude. J ournal of Pathology, 104: 231-238.

4. Arias-Stella J \& Bustos F (1976). Chronic hypoxia and chemodectomas in bovines at high altitudes. Archives of Pathology and Laboratory Medicine, 100: 633-639.

5. Barer GR, Edwards CW \& J olly Al (1976). Changes in the carotid body and the ventilatory response to hypoxia in chronically hypoxic rats. Clinical Science and M olecular Medicine, 50: 311-313.

6. Dhillon DP, Barer GR \& Walsh M (1984). The enlarged carotid body of the chronically hypoxic and hypercapnic rat: a morphometric analysis. Quarterly J ournal of Experimental Physiology, 69: 301-317.

7. Pallot DJ (1987). The mammalian carotid body. Advances in Anatomy, Embryology and Cell Biology, 102: 1-91.

8. Clarke J A, Daly M deB \& Ead HW (1990). Comparison of the size of the vascular compartment of the carotid body of the fetal, neonatal and adult cat. Acta Anatomica, 138: 166-174.

9. Clarke J A, Daly MdeB, Ead HW \& Kreclović G (1993). A morphological study of the size of the vascular compartment of the carotid body in a non-human primate (Cercopithicus ethiopus), and a comparison with the cat and rat. Acta Anatomica, 147: 240-247.

10. Clarke J A, Daly M deB, Marshall J M \& Ead HW (1996). A comparison of the size of the vascular compartment of the carotid body in normal, chronically hypoxic and diabetic rats. J ournal of Physiology, 495: 29P (Abstract).

11. Clarke J A, Daly MdeB, Ead HW \& Hennessy EM (1999). The carotid body in the spontaneous insulin-dependent diabetic rat. Brazilian J ournal of Medical and Biological Research, 32: 85-91.

12. Clarke J A \& Daly MdeB (1981). A comparative study of the distribution of carotid body type-1 cells and periadventitial type-1 cells in the carotid bifurcation regions of the rabbit, rat, guinea-pig and mouse. Cell and Tissue Research, 220: 753-772.

13. Mian R \& Marshall J M (1996). The behaviour of muscle microcirculation in chronically hypoxic rats: the role of adenosine. J ournal of Physiology, 491: 489-498.

14. Stata Corp. (1997). Stata Statistical Software: Release 50. Stata Corporation, College Station, TX.

15. Clarke J A, Duff MJ B \& Ip HH-S (1983). Reconstruction of the vascular system of the carotid body of the rat using an array processor. J ournal of Physiology, 341: 6P-7P.

16. Adams WE (1958). The Comparative Morphology of the Carotid Body and Carotid
Sinus. C.C. Thomas, Springfield, IL, 140142.

17. McGregor KH, Gil J \& Lahiri S (1984). A morphometric study of the carotid body in chronically hypoxic rats. J ournal of Applied Physiology, 57: 1430-1438.

18. Péquignot J $-M \&$ \&ellström $S$ (1983). Intact and sympathectomized carotid bodies of long-term hypoxic rats. Virchows Archives A, 400: 235-243.

19. Neylon $M, M$ arshall J $M$ \& J ohns EJ (1997). The effects of chronic hypoxia on renal function in the rat. J ournal of Physiology, 501.1: 243-250.

20. Adair TH, Gay WJ \& Montani J P (1990). Growth regulation of the vascular system: evidence for a metabolic hypothesis. American J ournal of Physiology, 259: R393-R404.

21. Bee D, Pallott DJ \& Barer GR (1986). Division of type 1 and endothelial cells in the hypoxic rat carotid body. Acta Anatomica, 126: 226-229.

22. Price RJ \& Skalak TC (1998). Arteriolar remodelling in skeletal muscle of rats exposed to chronic hypoxia. J ournal of Vascular Research, 35: 238-244.

23. Degner $F \&$ Acker H (1986). Mathematical analysis of tissue $\mathrm{PO}_{2}$ distribution in the cat carotid body. Pflügers Archiv, 407: 305-311.

24. Busse R, Förstermann U, Matzuda $\mathrm{H} \&$ Pohl U (1984). The role of prostaglandins in the epithelium-mediated vasodilatory response to hypoxia. Pflügers Archiv, 401: 77-83. 
25. Burnstock $G \&$ Ralevic $V$ (1994). New insights into the local regulation of blood flow by perivascular nerves and endothelium. British J ournal of Plastic Surgery, 47: 527-543.

26. Heath $D$, Edwards $C$, Winson $M \&$ Smith $P$ (1973). Effects on the right ventricle, pulmonary vasculature, and carotid bodies of the rat of exposure to, and recovery from, simulated high altitude. Thorax, 28 : 24-28.

27. Gilbert SF (1997). Developmental Biology. 5th edn. Sinauer Association, Inc., Sunderland, MA, 284-297.

28. Creazzo TL, Godt RE, Leatherburg L, Conway SJ \& Kirby ML (1998). Role of cardiac neural crest cells in cardiovascular development. Annual Review of Physiology, 60: 267-286.

29. Smith CA, Bisgard GE, Nielsen AM, Daristotle L, Kressin NA, Forster HV \& Dempsey J A (1986). Carotid bodies are required for ventilatory acclimatization to chronic hypoxia. J ournal of Applied Physiology, 60: 1003-1010.

30. Bisgard GE (1994). The role of arterial chemoreceptors in ventilatory acclimati- zation to hypoxia. Advances in Experimental Medicine and Biology, 360: 109-122.

31. Vizek M, Pickett CK \& Weil JV (1987). Increased carotid body hypoxic sensitivity during acclimatization to hypobaric hypoxia. J ournal of Applied Physiology, 63: 2403-2410.

32. Nielsen AM, Bisgard GE \& Vidruk EH (1988). Carotid chemoreceptor activity during acute and sustained hypoxia in goats. J ournal of Applied Physiology, 65: 1796-1802.

33. Barnard $P$, Andronikou S, Pokorski M, Smatresk N, Mokashi A \& Lahiri S (1987). Time-dependent effect of hypoxia on carotid body chemosensory function. J ournal of Applied Physiology, 63: 685-691.

34. Bouverot $P \&$ Bureau M (1975). Ventilatory acclimatization and CSF acid-base balance on carotid chemodenervated dogs at 3,550 m. Pflügers Archiv, 361: 17-23.

35. Lahiri S, Smatresk N, Pokorski M, Barnard P \& Mokashi A (1983). Efferent inhibition of carotid body chemoreception in chronically hypoxic cats. American J ournal of Physiology, 245: R678-R683.

36. O'Regan RG \& Majcherczyk S (1983).
Control of peripheral chemoreceptors by efferent nerves. In: Acker $\mathrm{H} \&$ O'Regan RG (Editors), Physiology of the Peripheral Arterial Chemoreceptors. Elsevier, Amsterdam, 257-298.

37. Acker $\mathrm{H}$, Lübbers $\mathrm{DW} \&$ \& Purves $\mathrm{MJ}$ (1971). Local oxygen tension field in the glomus-caroticum of the cat and its change at changing arterial $\mathrm{PO}_{2}$. Pflügers Archiv, 329: 136-155.

38. Krogh A (1919). The number and distribution of capillaries in muscles with calculations of the oxygen pressure head necessary for supplying the tissue. J ournal of Physiology, 52: 409-415.

39. Dempsey JA, Forster HV, Bisgard GE, Chosy LW, Hanson PG, Kiorpes AL \& Pelligrino DA (1979). Role of cerebrospinal fluid $\left(\mathrm{H}^{+}\right)$in ventilatory deacclimatization from chronic hypoxia. J ournal of Clinical Investigation, 64: 199-205.

40 Engwall MJ A \& Bisgard GE (1990). Ventilatory responses to chemoreceptor stimulation after hypoxic acclimatization in awake goats. J ournal of Applied Physiology, 69: 1236-1243. 